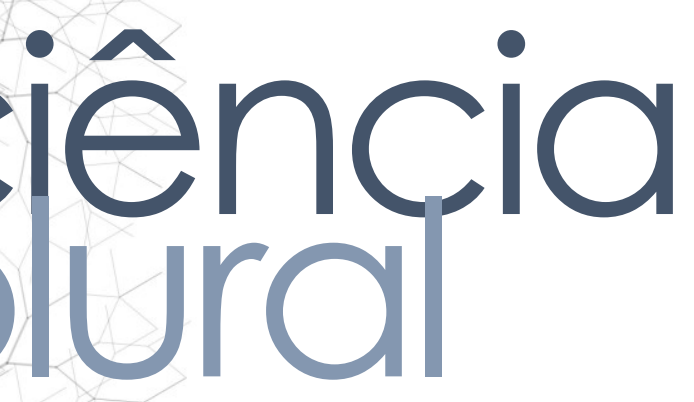

\title{
ANÁLISE DA CONDIÇÃO DE SAÚDE BUCAL DA POPULAÇÃO EM SITUAÇÃO DE RUA DO MUNICÍPIO DE NATAL-RN
}

Analysis of the oral health condition of the homeless population of the city of Natal-RN

Análisis de la condición de salud oral de la población callejera de la ciudad de Natal-RN

Silas Sarkiz da Silva Martins • Cirurgião-Dentista pela UFRN • E-mail: silas_sarkiz@hotmail.com

Edna Maria da Silva • Professora Titular do Departamento de Odontologia da UFRN•E-mail: edna@reitoria.ufrn.br

Autor responsável pela correspondência:

Silas Sarkiz da Silva Martins • E-mail: silas_sarkiz@hotmail.com 


\section{RESUMO}

Introdução: Devido à problemática da desigualdade social, tem-se observado nas últimas décadas o aumento da chamada População em Situação de Rua (PSR), a qual sofre com a invisibilidade e a exclusão social. As condições de vida dessa população oferecem diversos riscos à sua saúde. A saúde bucal está entre os principais problemas de saúde referidos, porém há uma carência de informações epidemiológicas que representem as especificidades desse grupo populacional. Objetivo: Estudar a condição de saúde bucal da PSR do município de Natal-RN. Metodologia: Estudo quantitativo observacional e transversal, realizado no Centro de Referência Especializado para PSR (Centro POP). Foram examinadas 60 pessoas, selecionadas de forma aleatória. Utilizou-se um questionário estruturado sobre os hábitos de higiene bucal e dieta, além de exame clínico bucal para verificar a história e a atividade de cárie (CPO-D), doença periodontal (CPI) e a ocorrência de lesões em tecidos moles. Os dados foram tabulados e analisados descritivamente no software SPSS. Resultados: A média de idade foi de 41,43 anos $( \pm 11,19)$; o sexo masculino correspondeu a $86,7 \%$ e o feminino $13,3 \%$. Sobre o tempo de rua, obteve-se uma média de 7,42 anos $( \pm 8,29)$. A média do CPO-D foi de 15,35, sendo os componentes cariados, perdidos e restaurados, respectivamente: 3,93; 9,13 e 2,30. A condição periodontal mais prevalente, por sextante, foi o cálculo dentário (média=3,82), seguido pelo sangramento gengival (média $=3,52$ ), bolsa rasa (média $=1,27$ ) e bolsa profunda (média $=0,40)$. Em relação ao pior escore do CPI, verificou-se que $46,7 \%$ apresentaram bolsa rasa, 26,7\% bolsas profundas e 16,7\% cálculo dentário. Dos examinados, 15\% apresentaram lesões em tecidos moles. Conclusões: A prevalência de cárie e doença periodontal foi elevada. Notou-se uma maior severidade dessas doenças e dificuldade de acesso à assistência odontológica, constatando que o modo de vida dessa população influencia na forma como as principais doenças bucais repercutem sobre eles.

Palavras-Chave: Pessoas em Situação de Rua; Saúde Bucal; Diagnóstico Bucal.

\section{ABSTRACT}

Introduction: Due to the problem of social inequality, in recent decades there has been an increase in the number of homeless people (HP), who suffer from invisibility and social exclusion. The living conditions of this population pose several health risks. Oral health is among the main health problems mentioned, but there is a lack of epidemiological information that represents the specificities of this public. Objective: To study the oral health condition of HP in Natal-RN city. Methodology: Quantitative cross-sectional study, carried out at the Specialized Reference Center for HP (POP Center). 60 people were evaluated, randomly selected. A structured questionnaire about oral hygiene habits and diet was used, as well as oral clinical examination to verify the history and activity of caries (CPO-D), periodontal disease (CPI) and the occurrence of soft tissue lesions. The data were tabulated and analyzed descriptively SPSS software. Results: The mean age was 41.43 years $( \pm 11.19)$; the males orresponded to $86.7 \%$ and the females to $13.3 \%$. About street's time, a mean of 7.42 ears $( \pm 8.29)$ was obtained. The CPO-D mean was 15.35 , being the components cayed, lost and restored, respectively: 3.93; 9.13 and 2.30. The most prevalent riodontal condition, by sextant, was the dental calculus (mean $=3.82$ ), followed by 


\section{ciênciála
pural}

gingival bleeding $($ mean $=3.52)$, shallow pocket $($ mean $=1.27)$ and deep pocket $($ mean $=0,40$ ). In relation to the worst CPI score, it was found that $46.7 \%$ had a shallow pocket, $26.7 \%$ deep pocket, and $16.7 \%$ dental calculus. Of those examined, $15 \%$ had soft tissue lesions. Conclusions: The prevalence of caries and periodontal disease was high. It was noted a greater severity of these diseases and difficulty of access to dental care, noting that the way of life of this population influences the way the main oral diseases affect them.

Keywords: Homeless Persons; Oral Health; Oral Diagnosis.

\section{RESUMEN}

Introducción: Debido a la problemática de la desigualdad social, se ha observado en las últimas décadas el aumento de la llamada población callejera (PC), que sufre invisibilidad y exclusión social. Las condiciones de vida de esta población plantean varios riesgos para su salud. La salud oral se encuentra entre los principales problemas de salud reportados, pero hay una falta de información epidemiológica que represente las especificidades de este grupo de población. Objetivo: Estudiar las condiciones de salud bucal de la población callejera de Natal-RN. Metodología: Estudio cuantitativo observacional y transversal realizado en el Centro de Referencia Especializado en PC (Centro POP). Sesenta personas seleccionadas al azar fueron examinadas. Se utilizó un cuestionario estructurado sobre higiene oral y hábitos alimenticios, así como un examen clínico oral para verificar el historial y la actividad de la caries (CPO-D), la enfermedad periodontal (CPI) y la aparición de lesiones de tejidos blandos. Los datos fueron tabulados y analizados descriptivamente utilizando el software SPSS. Resultados: El promedio de edad fue de 41.43 años $( \pm 11.19$ ); los hombres representaron el $86.7 \%$ y las mujeres el $13.3 \%$. A cerca del tiempo en las calles, se obtuvo un promedio de 7,42 años $( \pm 8,29)$. El CPO-D medio fue de 15.35, con componentes cariados, perdidos y restaurados, respectivamente: $3.93 ; 9.13$ y 2.30 . La afección periodontal más prevalente, por sextante, fue el cálculo dental (media $=3,82$ ), seguido de sangrado gingival (media $=3,52$ ), bolsa poco profunda (media $=1,27$ ) y bolsa profunda (media $=0,40$ ). Al respecto al peor puntaje del CPI, se encontró que $46.7 \%$ tenía bolsa poco profunda, $26.7 \%$ bolsa profunda y $16.7 \%$ cálculo dental. De los examinados, $15 \%$ tenían lesiones de tejidos blandos. Conclusiones: la prevalencia de caries y enfermedad periodontal fue alta. Se observó una mayor gravedad de estas enfermedades y dificultades de acceso a la atención dental, y se observó que el estilo de vida de esta población influye en la forma en que las principales enfermedades orales los afectan.

Palabras Claves: Personas sin Hogar; Salud Bucal; Diagnóstico Bucal. 


\section{Introdução}

A desigualdade social é um problema que afeta a todos os países, porém apresenta uma maior gravidade naqueles considerados subdesenvolvidos. Esse problema, ocorre como consequência do sistema capitalista, que potencializa a divisão de classes. Os centros urbanos brasileiros evidenciam essa condição através do aumento das favelas, residências improvisadas, desemprego, criminalidade e da dificuldade de acesso aos serviços básicos como educação, saúde, transporte e saneamento.

Diante desses fatores, tem-se observado o aumento da chamada População em Situação de Rua (PSR), definida pela Política Nacional para a População em Situação de Rua como "grupo populacional heterogêneo que possui em comum a pobreza extrema, os vínculos familiares interrompidos ou fragilizados e a inexistência de moradia convencional regular, e que utiliza os logradouros públicos e as áreas degradadas como espaço de moradia e de sustento, de forma temporária ou permanente, bem como as unidades de acolhimento para pernoite temporário ou como moradia provisória" 1.

Natalino² afirma que o Brasil não possui dados oficiais sobre a PSR, uma vez que não estão incluídos nos sensos nacionais e poucos são os municípios que têm incluído em suas contagens populacionais periódicas. Isso dificulta o planejamento e implementação de políticas públicas voltadas para essa população, que continua cada vez mais invisível no âmbito das políticas sociais.

Com o objetivo de caracterizar o perfil dessa população, foi realizada uma pesquisa nacional pelo Ministério do Desenvolvimento Social e Combate à Fome, no ano de $2008^{3}$. Foram identificadas 31.922 pessoas em situação de rua nas cidades pesquisadas. Apesar de tal estudo não incluir a PSR brasileira em sua totalidade, e ser relativamente antigo, ele ainda é referência base para conhecer as características dessa população a nível nacional4

O conceito ampliado de saúde foi criado para valorizar os determinantes sociais influenciam no processo saúde-doença, sendo consideradas as condições oeconômicas, demográficas, culturais e de acesso aos equipamentos sociais 5 . 
Assim, cada indivíduo, família, comunidade e grupo populacional apresenta necessidades e riscos específico à sua localização geográfica, estilo de vida e condição social; e estes aspectos se traduzirão em um perfil de problemas de saúde-doença peculiar. Desse modo, os estudos das desigualdades sociais em saúde constituem importante ferramenta para os serviços de saúde ${ }^{6}$.

Embora a Constituição Federal, em seu artigo 196, traga que a saúde é direito de todos e dever do estado e que o acesso deve ser universal e igualitário, a Pesquisa Nacional, citada anteriormente, revela que 18,4\% da PSR já passou por experiências de impedimento de receber atendimento na rede de saúde?

A vida na rua expõe as pessoas a problemas de saúde devido a vulnerabilidade à violência, a alimentação incerta e sem condições de higiene, a pouca disponibilidade de água potável, a privação de sono e afeição e a dificuldade de adesão a tratamento de saúde.7 A saúde bucal está entre os principais problemas referidos pela PSR, a qual apresenta um alto risco às desordens bucais, devido à ausência de local para realizar a higiene bucal, a falta de acesso a dentifrício, escova dentária e fio dentário, a instabilidade dietética, o uso de drogas, a condição de saúde mental e o desconhecimento sobre a importância da saúde bucal ${ }^{8}$.

Ainda há uma carência de informações epidemiológicas em saúde bucal que representem as especificidades desse público. Apesar de conhecermos a etiologia multifatorial das principais doenças bucais, sabemos que os determinantes sociais são capazes de mudar a forma como tais doenças se expressam na população, considerando sua heterogeneidade.

Por isso, faz-se importante conhecer a condição de saúde bucal da PSR, considerando os determinantes sociais que influenciam o processo saúde-doença na mesma. Dessa forma, será possível relacionar os achados clínicos com as condições de vida características dessa população; contribuindo para uma melhor caracterização de saúde bucal e, consequentemente, para que o órgão municipal competente possa lanejar e executar intervenções baseadas nas demandas desse grupo específico. 
Assim, este estudo teve como objetivo geral estudar a condição de saúde bucal da PSR da cidade de Natal-RN, através da verificação das prevalências de cárie e doença periodontal, e da ocorrência de lesões em tecidos moles.

\section{Metodologia}

O projeto foi aprovado pelo Comitê de Ética em Pesquisa da Universidade Federal do Rio Grande do Norte, obtendo o parecer 2.448 .379 e foi desenvolvido de acordo com as diretrizes e normas regulamentadoras da pesquisa envolvendo seres humanos que compõem a Resolução CNS 466/2012. Os indivíduos que aceitaram participar da pesquisa assinaram o Termo de Consentimento Livre e Esclarecido (TCLE), ocasião em que foram esclarecidos sobre os possíveis riscos, o resguardo da identidade, assim como objetivos e métodos adotados.

O estudo consistiu de uma abordagem quantitativa, observacional e transversal, realizado na Cidade de Natal, Rio Grande do Norte com a PSR que frequenta o Centro de Referência Especializado para População em Situação de Rua (Centro POP).

Foram considerados como elegíveis os indivíduos sem moradia convencional regular, e que utilizam os logradouros públicos como espaço de moradia e de sustento, assim como as unidades de acolhimento para pernoite temporário, com idade igual ou superior a 18 anos; o enquadramento na condição de PSR descrita anteriormente; e a assinatura do TCLE.

O cálculo da amostra foi realizado considerando dois indicadores básicos: a média do componente cariado do índice CPO-D para os grupos etários de 15 a 19 anos $(1,95)$ e 35 a 44 anos $(2,27)$, segundo a Pesquisa Nacional de Saúde Bucal (SB BRASIL) 2010 (faixa etária que concentra a maior parcela da PSR); e o dado oficial para a PSR de Natal (1.141), de acordo com a Secretaria Municipal de Trabalho de Assistência Social (SEMTAS). Assim, com base no estudo de Lwanga e Lemeshow ${ }^{9}$ e considerando ma margem de erro absoluta de 0,7\% foi obtida uma amostra de 71 (15-19 anos) e 82 -44 anos) totalizando 153 indivíduos em situação de rua. Todavia, por ocasião da eta de dados, verificou-se a repetição dos indivíduos já examinados; tendo-se 
encerrado a coleta com 60 participantes. A seleção dos indivíduos foi do tipo aleatória simples.

Para a coleta dos dados, foi realizado um exame clínico bucal (figura 1), a fim de verificar história e atividade de cárie, doença periodontal e ocorrência de lesão em tecidos moles, tomando como referência os índices utilizados no SB Brasil (CPO-D e CPI). Além disso, foi aplicado um questionário semiestruturado (figura 2), para coletar as informações gerais dos participantes, bem como seus hábitos de higiene bucal, dieta, uso de serviços odontológicos e escolaridade. Ressalta-se que ambos os instrumentos de pesquisa utilizados foram validados pelo SB Brasil 2010.

Figura 1 - Ficha de exame clínico.

\section{CARIE DENTARIA E NECESSIDADE DE TRATAMENTO}

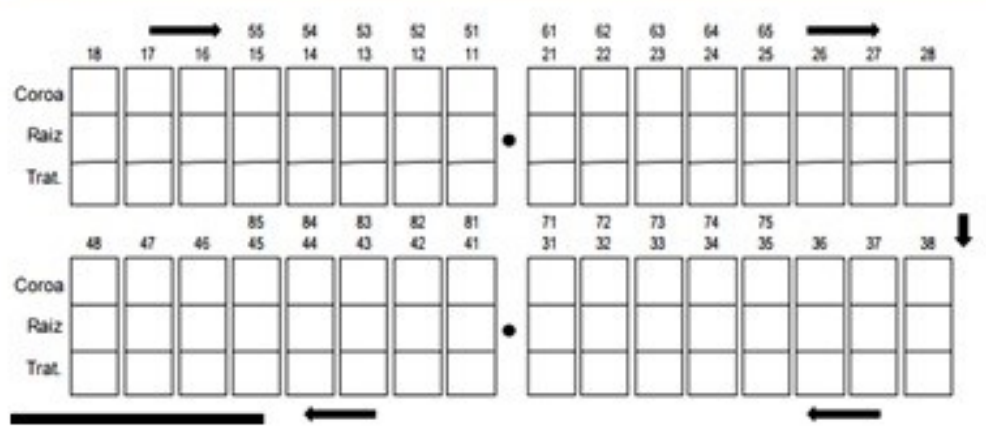

CONDIÇAO PERIODONTAL

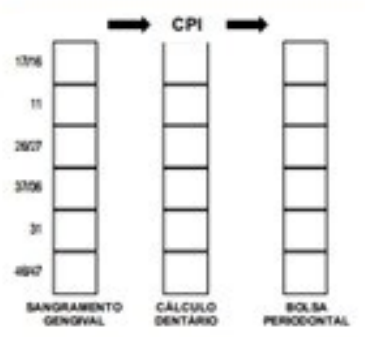

OCORRENCIA DE LESOESEMTECIDOS MOLES

$\operatorname{SIM}$

NÄO $\square$

Fonte: Adaptado de SBBrasil (2010). 
Figura 2 - Questionário

\section{INFORMAÇOES GERAIS}

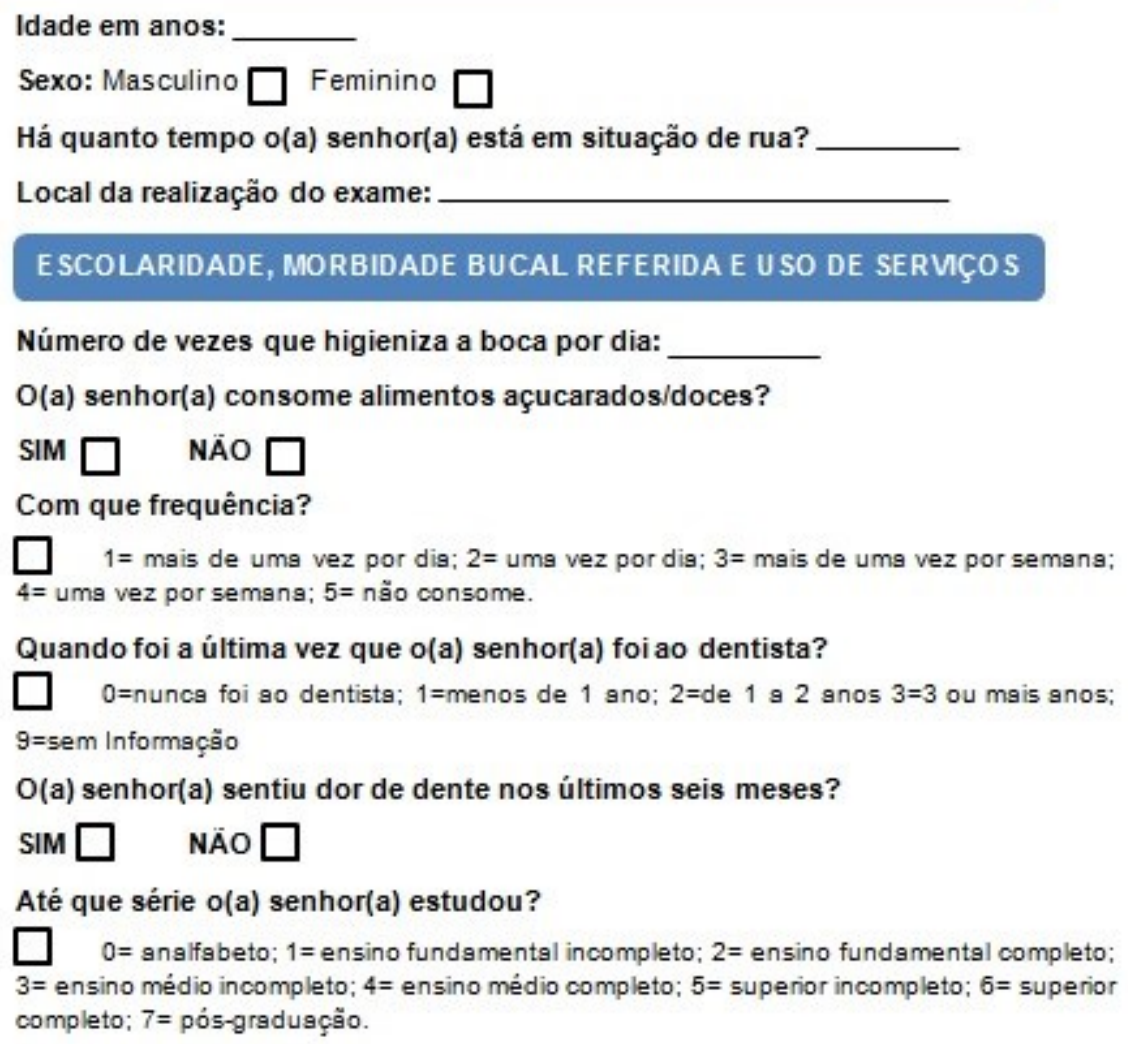

Fonte: Adaptado de SBBrasil (2010).

Os dados foram tabulados em um banco de dados do programa Statistical Package for Social Sciences (SPSS) 20.0 e analisados em função dos valores médios e variabilidade dos escores obtidos.

\section{Resultados}

A amostra analisada foi constituída por 60 PSR, com idade média de 41,43 anos $( \pm 11,19)$. Quanto ao sexo, houve uma maior prevalência do sexo masculino $(86,7 \%$, n=52) em relação ao sexo feminino $(13,3 \% ; n=8)$. Já em relação ao tempo em que as pessoas se encontravam em situação de rua, obteve-se uma média de 7,42 anos $( \pm 8,29)$. Para homogeneizar as frequências e facilitar as análises, a variável escolaridade foi ividida em dois grupos: até o ensino fundamental incompleto; e ensino fundamental mpleto e mais. Dessa forma, verificou-se que $60 \%(n=36)$ não completaram o ensino damental, e desses, 4 eram analfabetos e 32 cursaram o ensino fundamental de 
forma incompleta. Uma amostra equivalente a $40 \%(\mathrm{n}=24)$ representa o segundo grupo; desses, 12 cursaram o ensino fundamental de forma completa; 2 o ensino médio incompleto; 9 o ensino médio completo e 1 o ensino superior completo.

\section{Perfil de Saúde Bucal da PSR do Município de Natal-RN:}

Foi definido o perfil de saúde bucal em função da experiência de cárie e doença periodontal, expressas pelos índices CPO-D e CPI, hábitos de higiene bucal; frequência de consumo de alimentos cariogênicos; dor de dente e última consulta ao dentista.

Sobre os hábitos de higiene, 56,7\% ( $n=34)$ relataram que higienizavam a boca duas vezes ou mais por dia (duas vezes $n=22$; três vezes $n=11$; quatro vezes $n=1$ ), enquanto $43,3 \%(n=26)$ disseram higienizar a boca menos de duas vezes por dia (nenhuma vez $n=4$; uma vez $n=22$ ).

Quando perguntados sobre a frequência que consomem alimentos cariogênicos, $50 \%(n=30)$ disseram consumir diariamente, enquanto a outra metade relatou consumir raramente ou não consumir (não consome n=21).

Ao analisar se a população tinha acesso regular aos serviços de saúde, verificouse que, em relação à consulta ao dentista, $5 \%(n=3)$ disseram nunca ter ido ao dentista, $38,3 \%(n=23)$ disseram ter ido há menos de três anos e 56,7\% (n=34) relataram ter ido há três anos ou mais. Analisando a dor de dente, verificou-se que 41,7\% (n=25) afirmaram ter sentido dor de dente nos últimos seis meses.

Ao buscar estabelecer o perfil epidemiológico das doenças biofilme dependentes, tem-se que, em relação à cárie dentária: a média do CPO-D na amostra estudada foi de 15,35. Para os componentes cariados, perdidos e restaurados, as médias foram respectivamente: 3,93; 9,13 e 2,30. Em relação aos dentes hígidos, a média foi de 11,50 .

Sobre a necessidade de tratamento para a cárie dentária, as médias para atamento restaurador e exodontia foram, respectivamente, 3,53 e 1,78. Poucos mentos dentários apresentaram necessidade de tratamento endodôntico (média = $0,08)$. 
Ao estudar a condição periodontal dos indivíduos analisados, a partir da avaliação de cada sextante, pôde-se obter a prevalência de cada componente do CPI. A alteração periodontal mais prevalente foi o cálculo dentário (média=3,82), seguido pelo sangramento gengival (média $=3,52$ ), presença de sextantes com bolsa rasa (média=1,27) e profunda (média=0,40).

Em relação ao pior escore do CPI, verificou-se que nenhuma das pessoas em situação de rua avaliadas apresentou algum sextante hígido e 10\% apresentaram os sextantes excluídos como pior escore. A presença de bolsa rasa foi a condição mais expressiva, presente em 46,7\% dos examinados. Além disso, 26,7\% tinham bolsas periodontais profundas e 16,7\% apresentaram o cálculo dentário como o pior escore. Apesar de presente, o sangramento gengival não foi o pior escore para nenhum dos examinados.

Quando avaliada a presença de lesões em tecidos moles, observou-se que 85\% $(n=51)$ dos examinados não apresentaram lesões. Os demais apresentaram lesões como: úlcera traumática $(n=3)$, exostose $(n=2)$, lesão pigmentada associada à queilite actínica $(n=1)$, leucoplasia $(n=1)$; candidíase $(n=1)$ e língua fissurada $(n=1)$. Os indivíduos que apresentaram lesões com reconhecido potencial de malignidade foram encaminhados ao serviço de Estomatologia do Departamento de Odontologia da Universidade Federal do Rio Grande do Norte.

\section{Discussão}

A partir da análise detalhada dos resultados, verificou-se que a média da idade das pessoas incluídas na amostra condiz com as informações disponíveis na literatura hacional e internacional, conforme mostram os estudos de Figueiredo, Hwang e Quiñonez ${ }^{10}$, o qual teve uma média de idade de 39 anos (18 - 75); e Daly et al. ${ }^{11}$, cuja média foi de 39,5 anos (19 - 77). A Pesquisa Nacional Sobre a População em Situação Rua (PNPSR), indica que mais da metade (53\%) das pessoas adultas em situação de encontra-se na faixa etária de 25 a $44 \operatorname{anos}^{3}$. 
A predominância do sexo masculino observada também corrobora com diversos estudos sobre PSR, como os de Freitas et al. ${ }^{12}$, Hill e Rimington ${ }^{13}$ e Silveira e Stanke ${ }^{14}$, nos quais o sexo masculino correspondeu a $77 \%, 87 \%$ e $80 \%$, respectivamente. A PNPSR também evidencia essa predominância $(82 \%)^{3}$.

Em relação ao tempo de rua, a PNPSR mostra que cerca de $31 \%$ das pessoas vivem nessa condição há mais de 5 anos. $^{3} \mathrm{O}$ estudo de Figueiredo, Hwang e Quiñonez ${ }^{10}$ apresentou uma média de tempo de rua de 4 anos. Para Silveira e Stanke ${ }^{14}$ a média de tempo na rua foi de 9 anos e 8 meses.

Silveira e Stanke ${ }^{14}$ destacam que a condição de morador de rua é intercorrente, havendo períodos em que o indivíduo retorna ao âmbito familiar, mas com frequência acabam voltando às ruas. Por outro lado, a PNPSR informa que a questão do tempo de permanência na rua merece destaque, já que parece ser uma situação que facilmente se torna crônica ${ }^{3}$.

Os dados sobre escolaridade obtidos neste estudo foram bem similares aos que demonstra a PNPSR, em que a maior parte (63,5\%) não concluiu o ensino fundamental, todavia, pessoas com nível superior estão atualmente em situação de rua. ${ }^{3}$ Os dados de Silveira e Stanke ${ }^{14}$ também foram similares: 54\% apresentaram o ensino fundamental incompleto.

Ao analisar os dados sobre os hábitos de higiene bucal, observa-se que os que disseram higienizar a boca duas vezes ou mais por dia foram maioria, porém, esses hábitos não foram confirmados durante o exame clínico bucal. Silveira e Stanke ${ }^{14}$ detectaram um percentual médio de $85 \%$ para o índice de placa visível, sendo que 20\% dos examinados tiveram índice de 100\%, confirmando que, quando avaliada clinicamente, constata-se que a higiene bucal dessa população é precária.

A PNPSR destaca a falta de locais adequados para realização de higiene e mostra que, em relação ao banho e as necessidades fisiológicas, por exemplo, os principais locais utilizados são a rua, os albergues/abrigos, os banheiros públicos, os tabelecimentos comerciais e a casa de parentes ou amigos. Na maior parte dos casos, recursos disponíveis para a higiene pessoal desta população são precários e róprios, podendo ocasionar problemas de saúde ${ }^{3}$. Freitas et al. ${ }^{12}$ relatam que as 
pessoas que vivem em situação de rua têm recursos inadequados para a higiene bucal regular.

Em relação à alimentação, as pessoas foram questionadas sobre a frequência de ingestão de alimentos "açucarados", a fim de relacionar os hábitos alimentares com a cárie dentária, uma vez que a sacarose age como substrato às bactérias precursoras dessa doença. Porém, a alimentação é um ponto crítico para essa população. Segundo a Pesquisa Nacional já citada, 79,6\% das PSR conseguem fazer ao menos uma refeição ao dia, e 19\% não conseguem. Assim, confirma-se que a alimentação não é feita selecionando o alimento de acordo com seu valor nutricional (mais saudável), mas sim aceitando o que lhes é disponibilizado 3 .

Sobre o acesso aos serviços de saúde, a PSR enfrenta um grande problema, que é a discriminação. É importante destacar que entre essa população são recorrentes os relatos de recusa em ir para unidades de saúde devido a episódios de mau atendimento em hospitais, de negação a atendimento e impedimento de entrada nas unidades de saúde. Um dado que confirma essas alegações foi trazido pela Pesquisa Nacional, que revela que $18,4 \%$ dessas pessoas já passaram por experiências de impedimento de receber atendimento na rede de saúde ${ }^{3,7}$.

O Manual Sobre o Cuidado à Saúde Junto a PSR fala que a abordagem e o acolhimento são de fundamental importância para a produção do cuidado, tendo em vista que esse grupo social é historicamente marcado por um processo de exclusão dos serviços de saúde, onde a sua presença se traduz em forte incômodo tanto para os profissionais de saúde quanto para os demais usuários, ficando quase sempre renegado o seu direito à atenção integral à saúde e, quando muito, apenas é atendido nas emergências. Esse mesmo manual destaca as dificuldades dessa população em encontrar o local adequado para procurar assistência8.

Em relação ao acesso à assistência odontológica, o estudo de Freitas et al. ${ }^{12}$ revela que $40,3 \%$ dos participantes foi pela última vez ao dentista há mais de 5 anos e $4 \%$ há mais de 1 ano e menos de 5 anos; revelando que apenas uma pequena parcela $7,5 \%$ ) dessa população teve acesso ao dentista no último ano. Figueiredo, Hwang e iñone ${ }^{10}$ também mostram, em seu estudo, dados sobre a última visita ao dentista; 
eles verificaram que 35,6\% dos participantes foram do dentista pela última vez há 4 anos ou mais; 29,8\% foram há 1 ano ou menos de 4 anos; e 32,5\% foram há menos de 1 ano. Assim, os resultados deste estudo corroboram com a literatura, quando evidencia que somente a minoria dos participantes teve o último acesso ao dentista recentemente.

No que diz respeito à dor de dente nos últimos 6 meses, este estudo demonstrou uma prevalência de quase metade dos participantes. $\mathrm{O}$ estudo de Freitas et al. ${ }^{12}$ teve uma prevalência de 54,6\% de dor de dente nos últimos 6 meses; além disso, 28,9\% disseram que a dor os impediu de comer e 20,9\% de dormir. Hill e Rimington ${ }^{13}$ destacam em seu estudo que a principal razão para a procura de atendimento odontológico foi a dor dentária (94\%). Já Silveira e Stanke ${ }^{14}$ relatam que 93\% já tiveram ou apresentam dor de dente, adotando medidas extremas como tentativa de extração do dente por conta própria com o uso de alicate, faca ou outro meio.

Observou-se uma relação entre última consulta ao dentista e a dor de dente nos últimos 6 meses, de modo que a dor foi mais relatada no grupo de pacientes que procuraram atendimento mais recentemente, o que concorda com os dados de Hill e Rimington $^{13}$, de que a dor é a principal razão para procura de atendimento.

A análise dos resultados acerca da cárie dentária implica em conhecer os dados do SB Brasil 2010, os quais fornecem o diagnóstico da saúde bucal da população em geral. Assim, tem-se que a média do CPO-D para a faixa etária de 35 a 44 anos no município de Natal-RN, de acordo com o levantamento nacional, foi 19,09, e as médias dos componentes cariado (somando os componentes "cariado" e "restaurado, porém cariado", como feito neste trabalho), perdido e restaurado foram, respectivamente: 2,09; 9,36 e 7,65. A média de dentes hígidos foi de 12,2215.

Pode-se perceber que a média do CPO-D deste estudo $(15,35)$ foi inferior à encontrada na população em geral. O componente cariado, por outro lado, foi superior PSR $(3,93)$. O componente perdido $(9,13)$ foi bem próximo ao encontrado na esquisa Nacional, já o componente restaurado foi bem inferior na população tudada $(2,30)$, quando comparado com a população em geral. Em relação à média de tes hígidos, obteve-se um valor (11,50) próximo ao encontrado no SB Brasil 2010. 
Esses dados apresentam grande importância, pois demonstram características da experiência de cárie, bem como do tipo de assistência odontológica recebida. Isso reflete a dificuldade da PSR em receber assistência odontológica, por isso apresentam mais dentes cariados e menos dentes tratados com restauração, quando comparados com a população em geral. Apesar de a média do componente perdido ser bem próxima para ambas as populações, é importante lembrar que o CPO-D médio da PSR foi menor que o da população em geral. Isso sugere que a PSR, proporcionalmente, tem sido mais submetida ao tratamento mutilador do que a população em geral.

Ao analisar o que mostra a literatura, tem-se que o estudo de Silveira e Stank ${ }^{14}$ apresentou os seguintes resultados: média do CPO-D 16,3, sendo 2,6 para o componente cariado; 10 para perdidos e 4,6 para restaurados. Já o estudo de Daly et al. ${ }^{11}$ demonstrou o seguinte: média do CPO-D 15,5, sendo os componentes cariado 4,2; perdido 6,8 e restaurado 4,6. Figueiredo, Hwang e Quiñonez ${ }^{10}$ obtiveram em seu estudo uma média de CPO-D de 14,4, sendo os componentes cariado 6,3; perdido 4,6 e restaurado 3,5. Observa-se que a média do CPO-D visualizada neste estudo é similar às encontradas na literatura, contudo, os componentes do índice demonstram variação. Ressalta-se que, dos estudos citados, o de Silveira e Stanke ${ }^{14}$ foi o único realizado no Brasil, e é o que apresenta componente perdido mais próximo do obtido neste estudo, demonstrando que a assistência odontologia brasileira ainda realiza muitas exodontias frente aos tratamentos mais conservadores.

Em relação à necessidade de tratamento para a cárie dentária, os resultados apresentados pelo SB Brasil 2010 demonstram uma média de 1,9 dentes com necessidade de restauração; 0,12 necessitando de tratamento endodôntico e 0,51 de extração. Esses dados diferem dos encontrados neste estudo, os quais se mostraram superiores, principalmente no que se refere ao tratamento restaurador e à extração. Isso confirma o fato de que a PSR apresenta maior severidade de cárie que a população geral, e demonstra a dificuldade dessa população para obter assistência dontológica, pois, se o acesso fosse facilitado, o profissional conseguiria intervir cocemente no ciclo da doença e não haveria essa média de dentes com extração dicada $^{15}$. 
A baixa média de indicação de tratamento endodôntico obtida neste estudo pode ser explicada pelo alto componente perdido do CPO-D. Isso sugere que as exodontias estão sendo realizadas quando o dente apresenta comprometimento pulpar. Sabe-se que o tratamento endodôntico não é realizado nas unidades de saúde, devendo o paciente ser encaminhado ao Centro de Especialidades Odontológicas, porém, existe uma grande demanda nesse serviço. A dificuldade de acesso ao serviço especializado, somada às características da PSR, tem culminado na realização de extrações de dentes que poderiam ser salvos.

O estudo realizado por Ford, Cramb e Farah ${ }^{16}$ mostra que 91\% dos indivíduos avaliados necessitavam de tratamento restaurador, incluindo o tratamento endodôntico, e 62\% tinham indicação de extração. A necessidade de tratamento restaurador também foi mais prevalente para os estudos de Figueiredo, Hwang e Quiñonez ${ }^{10} 88 \%$ e Daly et al. ${ }^{11} 76 \%$. Hill e Rimington ${ }^{13}$ aplicaram um questionário com dentistas que atendiam PSR na Europa; eles constataram que 76,5\% dos tratamentos odontológicos realizados foram extrações e 58,8\% restaurações. Isso mostra que, apesar de a maior necessidade ser de tratamento restaurador, existe uma tendência em se realizarem extrações.

A doença periodontal também foi estudada na população brasileira pelo SB Brasil. Quanto ao pior escore do CPI, os dados para a população do Nordeste, na faixa etária de 35 a 44 anos, demonstraram: sangramento de 2,6\%; cálculo 26,2\%; bolsa rasa 13,1\%; bolsa profunda 2,8\% e excluído 37,3\%. Já em relação à média de sextantes afetados, nessa mesma população citada, tem-se: 1,18 para sangramento; 1,75 para cálculo; 0,52 para bolsa rasa e 0,08 para bolsa profunda ${ }^{15}$.

Verifica-se que os dados da população em geral diferem bastante dos encontrados neste estudo, uma vez que neste, a média de sextantes afetados foi superior para todas as condições. A única similaridade encontra-se no fato de o cálculo dentário ter sido a alteração mais prevalente, seguido pelo sangramento gengival, bolsa rasa e bolsa profunda. Além disso, ao se avaliar o pior escore do CPI, essa iferença também é evidente, uma vez que a bolsa rasa foi o pior escore mais 
prevalente neste estudo, seguido pela bolsa profunda, o cálculo dentário e sextantes excluídos.

Os dados obtidos evidenciam um estado periodontal preocupante na PSR. Percebe-se que 73,4\% dos indivíduos apresentam bolsa periodontal, a qual indica a doença no seu estágio avançado. Na análise de cada sextante, percebe-se outra situação preocupante, que é a média de quase 4 sextantes afetados pelo cálculo. Isso demonstra que a condição de higiene bucal é precária e reforça a necessidade de melhorar o acesso ao dentista para realização de uma terapia periodontal, a fim de remover os fatores retentivos de biofilme, orientar a higiene e, assim, conter a progressão da doença.

O tratamento periodontal foi verificado como necessário nos estudos de Ford, Cramb e Farah ${ }^{16}$ em 71\% dos indivíduos avaliados; Figueiredo, Hwang e Quiñonez ${ }^{10}$ em 70\%; e Daly et al. ${ }^{11}$ em $85 \%$. Silveira e Stanke ${ }^{14}$ também confirmam a severidade da condição periodontal na PSR; relatando em seu estudo que todos os indivíduos que possuíam dentes presentes apresentaram bolsa periodontal e sangramento gengival.

A presença de lesões em tecidos moles foi avaliada neste estudo, e verificou-se a ocorrência em 15\% (n=9) dos indivíduos avaliados. O estudo de Daly et al. ${ }^{11}$ também avaliou essa variável e observou que 9,28\% (n=9) apresentavam lesões na mucosa oral, que incluíam ulceração $(n=6)$, queilite angular $(n=1)$ e leucoplasia $(n=1)$. Já Silveira e Stanke ${ }^{14}$ destacaram a hiperplasia no palato devido à prótese mal adaptada e tuberosidade fibrosa.

A importância de se avaliar a presença de lesões em tecidos moles nessa população se dá pela relação entre estas e o uso de drogas. Hill e Rimington ${ }^{13}$ destacam que o uso de drogas pode causar necrose gengival, erosão dentária, leucoplasia, câncer oral e perfuração do septo nasal e do palato. Já Freitas et al. ${ }^{12}$ relatam que o uso de cocaína pode aumentar o risco de perda dentária por bruxismo e diminuição do $\mathrm{pH}$ salivar. Além disso, outro fator a ser considerado é que, devido à condição de vida dessa população, há uma frequente exposição à radiação solar, que é um dos principais fatores para o surgimento do câncer de lábio. 


\section{Conclusões}

A PSR do município de Natal-RN, objeto desse estudo, apresentou elevada prevalência e severidade de cárie e doença periodontal e pequena ocorrência de lesões em tecidos moles. Os fatores intrínsecos ao modo de vida dessa população influenciam na forma como as principais doenças bucais repercutem sobre eles, de conformidade com a teoria da determinação social do processo saúde-doença.

Considera-se a necessidade de políticas públicas específicas, que assegurem o acesso aos serviços de saúde, na perspectiva de uma atenção integral, de acordo com os pressupostos teóricos do Sistema Único de Saúde e a Constituição Federal do Brasil de 1988.

\section{Referências}

1 Brasil. Decreto presidencial no 7053, de 23 de dezembro de 2009. Institui a política nacional para a população em situação de rua e seu comitê intersetorial de acompanhamento e monitoramento, e dá outras providências [Internet]. Diário Oficial [da] República Federativa do Brasil. 2009 dez. 24 [acesso em 2017 mar 1 ]. Disponível em:http://www.planalto.gov.br/ccivil_03/_ato2007-2010/2009/decreto/d7053.htm.

2 Natalino MAC. Estimativa da população em situação de rua no Brasil. Brasília: Instituto de Pesquisa Econômica Aplicada; 2016.

3 Brasil. Ministério do Desenvolvimento Social e Combate à Fome. Pesquisa nacional sobre a população em situação de rua. Brasília: Ministério do Desenvolvimento Social e Combate à Fome; 2008.

Couto JGA. Atenção à saúde bucal da população em situação de rua: uma análise das ações nas capitais brasileiras da região sul [monografia]. Florianópolis: hiversidade Federal de Santa Catarina - UFSC; 2016. 
5 Brasil. Ministério da Saúde. VIII Conferência nacional de saúde: relatório final. Brasília: Ministério da Saúde; 1986.

6 Pereira AL. Influência da condição de saúde bucal na qualidade de vida dos indivíduos [monografia]. Campos Gerais: Universidade Federal de Minas Gerais; 2010.

7 Brasil. Ministério da Saúde. Saúde da população em situação de rua: um direito humano. Brasília: Ministério da Saúde; 2014.

8 Brasil. Ministério da Saúde. Manual sobre o cuidado à saúde junto a população em situação de rua. Brasília: Ministério da Saúde; 2012.

9 Lwanga SK, Lemeshow S. Sample size determination in health studies: a practical manual. Geneva: World Health Organization; 1991.

10 Figueiredo RLF, Hwang SW, Quiñonez C. Dental health of homeless adults in Toronto, Canada. J Public Health Dent. 2012 ago 13; 73(1): 74-78.

11 Daly B, Newton T, Batchelor P, Jones K. Oral health care needs and oral healthrelated quality of life (OHIP-14) in homeless people. Community Dent Oral Epidemiol. 2010 abr; 38(2): 136-144.

12 Freitas DJ, Kaplan LM, Tieu L, Ponath C, Guzman D, Kushel M. Oral health and access to dental care among older homeless adults: results from the HOPE HOME study. J Public Health Dent. 2018 set 17; 5(8): 1-7.

13 Hill KB, Rimington D. Investigation of the oral health needs for homeless people in specialist units in London, Cardiff, Glasgow and Birmingham. Prim Health Care Res Dev. 2010 out $28 ; 12(02):$ 135-144.

4 Silveira JLGC, Stanke R. Condição e representações da saúde bucal entre os semdo município de Blumenau - Santa Catarina. Cien Cogn. 2008; 13(1): 02-11. 


\section{ciência
purâl}

15 Brasil. Ministério da Saúde. SB Brasil 2010: Pesquisa nacional de saúde bucal: resultados principais. Brasília: Ministério da Saúde; 2012.

16 Ford PJ, Cramb S, Farah CS. Oral health impacts and quality of life in an urban homeless population. Aust Dent J. 2014 mai 26; 59(2): 234-239.

Submissão: 10/03/2019

Aceitação: 21/10/2019 